\title{
'Four-position method' makes beginner endoscopists aware of spatial positioning of the left hand to master upper gastrointestinal endoscopy $\square$
}

(이요 $\ominus$

\author{
Authors \\ Ken Sugimoto ${ }^{1}$, Satoshi Osawa² \\ Institutions \\ 1 First Department of Medicine, Hamamatsu University \\ School of Medicine, Hamamatsu, Japan \\ 2 Department of Endoscopic and Photodynamic Medicine, \\ Hamamatsu University School of Medicine, Hamamatsu, \\ Japan
}

submitted 23.2.2020

accepted after revision 19.5.2020

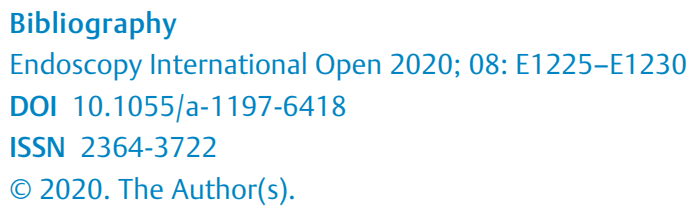
Commons Attribution-NonDerivative-NonCommercial License, permitting copying and reproduction so long as the original work is given appropriate credit. Contents may not be used for commecial purposes, or adapted, remixed, transformed or built upon. (https://creativecommons.org/licenses/by-nc-nd/4.0/)

Corresponding author

Ken Sugimoto, MD, First Department of Medicine, Hamamatsu University School of Medicine, 1-20-1 Handayama, Higashi-ku, Hamamatsu 431-3192, Japan Fax: +81534349447 sugimken@hama-med.ac.jp

\section{ABSTRACT}

Background and study aims We developed a novel "fourposition method" for facilitating endoscopy of the upper gastrointestinal tract, and this study aimed to verify its usefulness for beginner endoscopists.

Methods Medical students $(n=121)$ were divided into three groups. A simulator subsequently was used to perform endoscopy. Group A was taught how to hold the endoscope and move the dial; Group B was taught the "four-position method"; and Group C, in addition to being taught the "four-position method," was permitted to use an endoscope before introduction to the simulator. In each group, the transit time to various parts of the upper digestive tract was recorded in addition to the time to grasp a clip in the stomach with the forceps. We also surveyed the groups with respect to their impression of the difficulty level of endoscopic operation before and after instructions.

Results Transit time to the cardia was no different among the groups; however, with regard to other targets, Group C reached the sites significantly more quickly than did Groups A and B. Time to clip grasping was significantly shorter in Groups B and C than in Group A. Regarding the impression of the difficulty level, significantly more students in Groups $B$ and $C$ compared to Group A felt that endoscopy was easier after instructions.

Conclusion Learning the "four-position method" made it possible to achieve stable endoscopic manipulation at an early stage and improve subsequent endoscopic procedures.

\section{Introduction}

Upper gastrointestinal endoscopy is an indispensable procedure for gastroenterologists in clinical settings. Gastric cancer is abundant in Eastern Asian countries including Japan, and Barrett's esophageal cancer is increasing in those who are not infected with Helicobacter pylori; thus, the importance of upper gastrointestinal screening is increasing [1,2]. However, endoscopy is recommended for gastric cancer screening because gastric roentgenography is unlikely to identify cases of early-stage cancer that can be treated endoscopically [3]. However, there are insufficient numbers of gastrointestinal endoscopists to allow use of endoscopy as a mass screening for gastric cancer; thus, increasing the number of endoscopists is important. Therefore, acquiring technical skills and expertise in upper gastrointestinal endoscopy is highly desirable among beginners including primary care physicians [4-7].

To learn endoscopy hemostasis and tumor resection techniques such as polypectomy, endoscopic mucosal resection, and endoscopic submucosal dissection, it is necessary to learn basic endoscopy techniques including routine observation of the upper gastrointestinal tract and biopsy. However, it is diffi- 

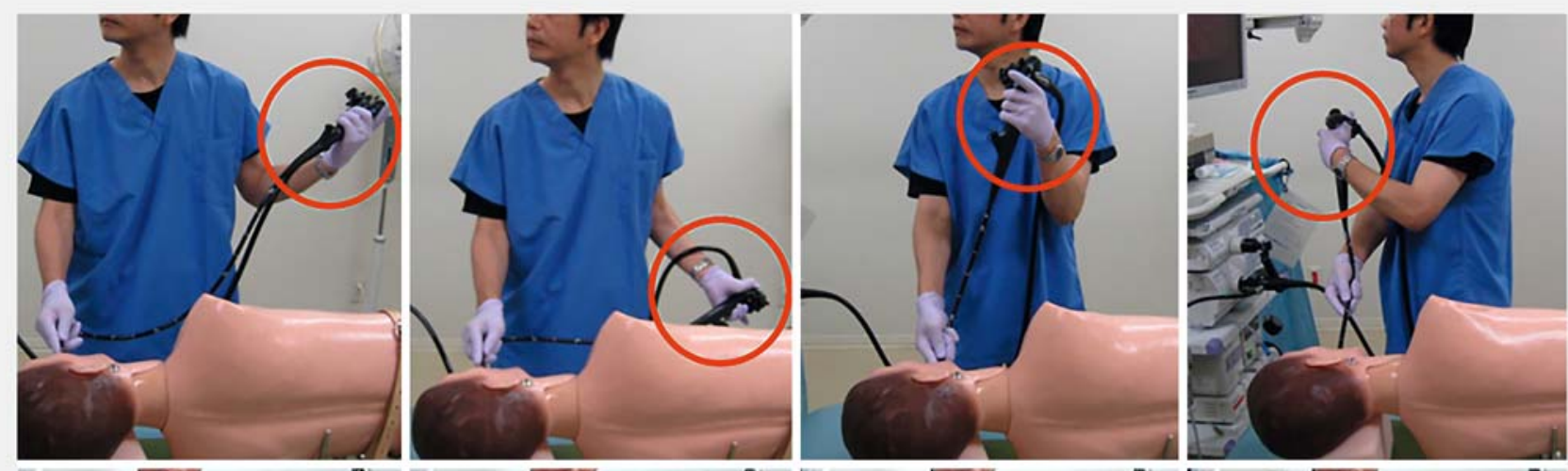

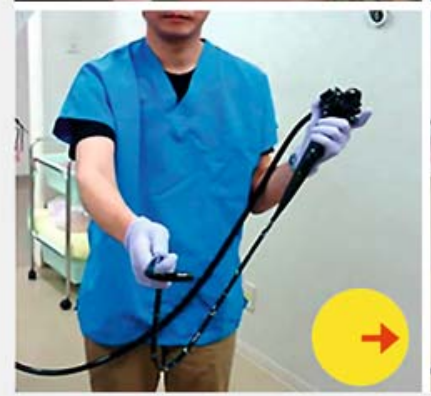

Position 1

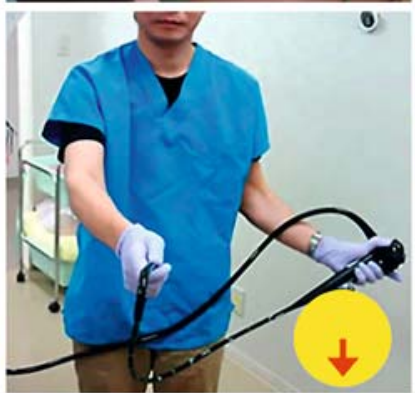

Position 2

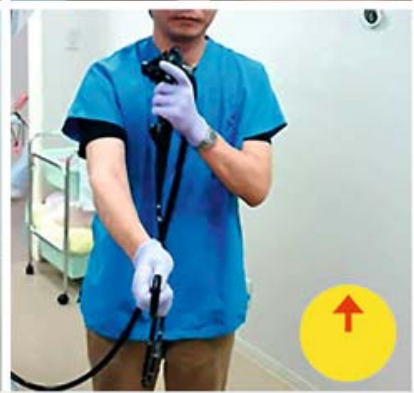

Position 3

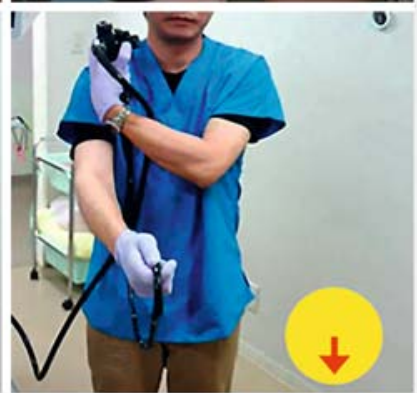

Position 4

- Fig. 1 "Four-position method" for teaching beginners how to operate the endoscope.

cult to learn endoscopy skills, and a certain amount of training time is required to be able to perform endoscopy sufficiently and practically [8].

Esophagogastroduodenoscopy is a relatively invasive procedure performed on the actual human body (subject), and it is difficult for residents, colleagues, and even instructors to practice endoscopy [9]. However, use of simulators can help improve practical endoscopy skills without requiring invasive procedures [10]. However, even when using a simulator, the criteria for evaluating endoscopy procedures are very subjective; therefore, it is very difficult for instructors to explain verbal and written instructions to beginners during endoscopy procedures $[9,10]$.

In fact, during endoscopy of the upper gastrointestinal tract, an expert endoscopist is able to change the left-hand position, dynamically moving it to rotate the tip of the scope by $360^{\circ}$ without twisting it with the right hand ( $\triangleright$ Fig. 1 and $\triangleright$ Video 1 ). However, there are few programs to teach beginner endoscopists that include left-hand positioning instruction. In the current study, we developed a novel teaching program that includes left-hand positioning instruction, the so-called four-position method, and evaluated its effectiveness in beginner endoscopists, specifically medical students.

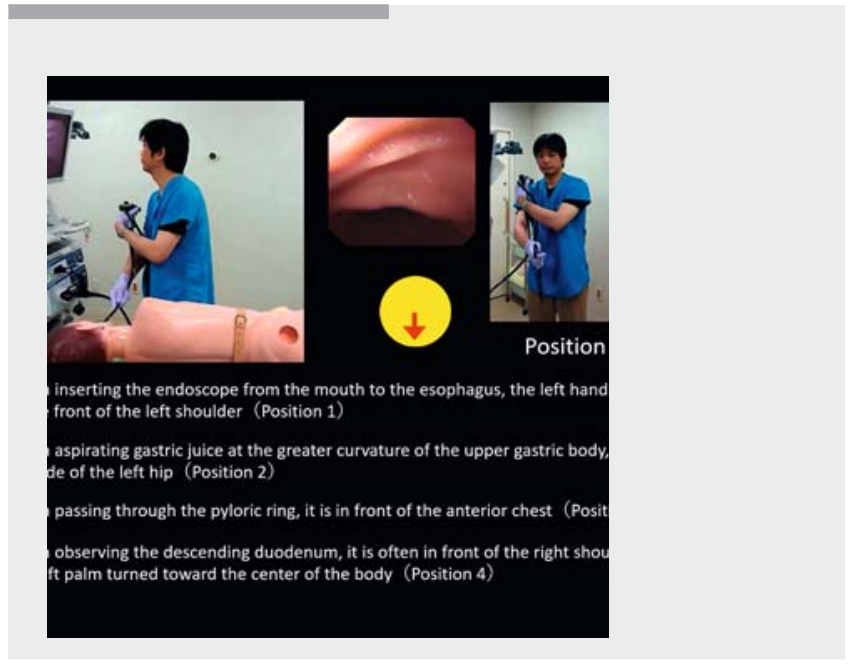

Video 1 Actual insertion method for the simulator using the four-position method.

\section{Methods}

\section{Research subjects}

From April 2017 to March 2018, 122 medical students undergoing medical clinical training at Hamamatsu University School of Medicine were included. A training time of 2 hours was set up once a week, and three to four students were taught and eval- 
uated. Endoscopy guidance and evaluation were provided by a doctor with 25 years of endoscopy experience.

\section{Equipment}

A Kyoto Kagaku CLA 4 simulator ( Fig. 2) and an Olympus EVIS LUCERA series (GIF-H260 esophagogastroduodenoscopy and CLV-260 processor) were used for the training.

\section{Four-position method}

- Fig. 1 shows the four-position method: Position 1, when inserting the endoscope, the left hand is at the front of the left shoulder; Position 2, when observing the greater curvature of the upper gastric body or fornix, the left hand is beside the left hip; Position 3, when passing through the pylorus, the left hand is in front of the chest; and Position 4, when observing the descending duodenum, the left hand is in front of the right shoulder with the left palm turned toward the body ( $\vee$ Video 1 ). When the dial of the endoscope is fixed in the up-angle direction, the tip of the endoscope is oriented in the 9 o'clock (leftward) direction in Position 1, 6 o'clock (downward) direction in Position 2, 12 o'clock (upward) direction in Position 3, and 6 o'clock (downward) direction in Position 4 ( $\triangleright$ Fig. 1 and $\triangleright$ Video 2).

\section{Study design}

Medical students were divided into three groups and instructed separately ( $\mathbf{F i g . 3}$ ). Randomization was performed using the envelope method. Students were classified from A to $C$ using the envelope method. As these tests were performed one-onone by one instructor and one student, and the other students were waiting outside the room, they were not allowed to observe their colleagues during the test. Group A was only taught how to hold the endoscope and move the dial; Group B was taught the four-position method; and Group C was taught the four-position method and permitted to practice it with an endoscope without using the simulator as shown in $\mathbf{v}$ Video 2 to become familiar with the positioning. Specifically, three to four students were instructed in one training session, in which the Group A, B, or C program was selected at random.

\section{Evaluation of endoscopy proficiency}

In each group, transit times were measured from the start of endoscope insertion to reaching the (1) cardia, (2) upper part of the stomach body, (3) pylorus, and (4) descending duodenum. A coin was placed on the cardia as shown in $\mathbf{V}$ Video $\mathbf{1}$, and the time when this coin was found on the endoscope screen was defined as the point where it reached the upper part of the stomach. Furthermore, a clip was placed at the fornix of the stomach, and the time to grasp it using forceps was measured from insertion of the endoscope and compared among groups. The grasping forceps used in this study are GF2323-WA- (Fuji Film, Kanagawa, Japan). The clip was placed by the instructor in the same location and in the same direction on the upper curvature of the stomach. This provided an environment in which all students could grasp clips under the same conditions. This experiment was conducted twice for each student.

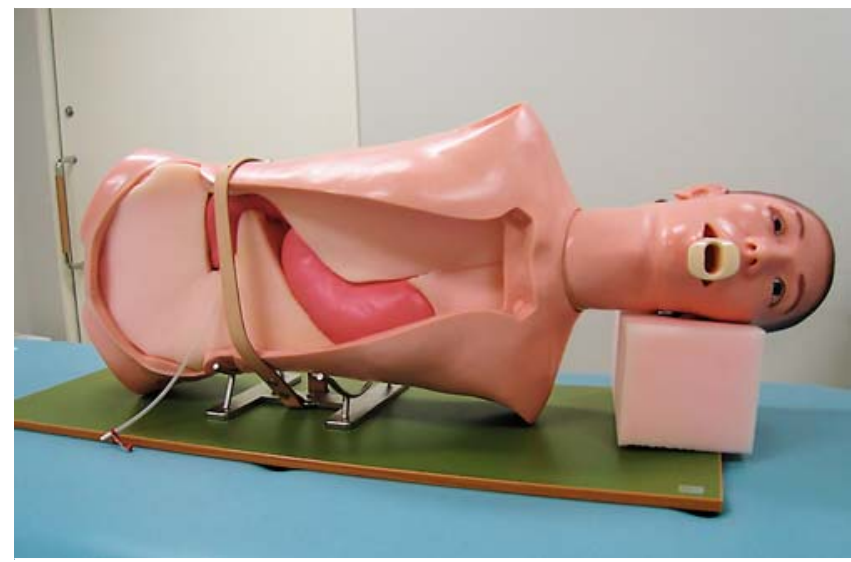

- Fig. 2 Simulator used to practice upper gastrointestinal endoscopy (Kyoto Kagaku CLA 4).

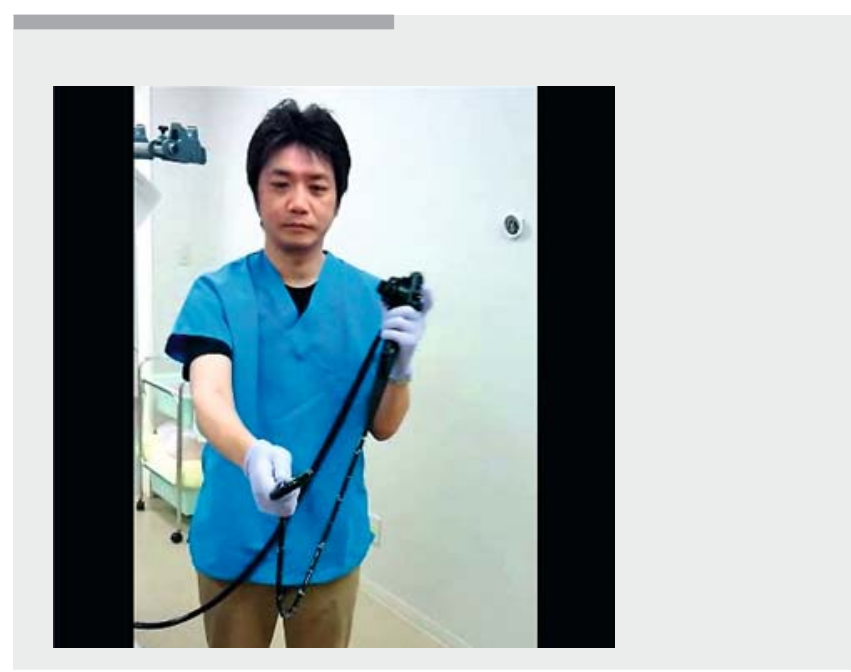

$\checkmark$ Video 2 Movement of the endoscope tip when performing the four-position method.

121 medical students with no endoscopy experience

$$
\begin{aligned}
& \begin{array}{l}
\text { Group A } \\
(\mathrm{n}=37)
\end{array} \\
& \begin{array}{l}
\text { Group B } \\
(\mathrm{n}=40)
\end{array} \\
& \begin{array}{l}
\text { Group C } \\
(\mathrm{n}=44)
\end{array} \text { Teach the "four the "four the use the endoscope only } \\
& \hline
\end{aligned}
$$

Fig. 3 Summary of the study design.

\section{Evaluation of perceived endoscopy difficulty}

Impressions of endoscopy before and after practical training were surveyed using the following questionnaire for students: 0 , very easy; 1 , easy; 2 , moderate; 3 , somewhat difficult; 4 , difficult; and 5 , very difficult. 


\section{Statistical analyses}

Statistical analysis was performed using SPSS statistical software (SPSS for Windows, Version 16.0, Ekuseru-Toukei 2010; Social Survey Research Information Co., Ltd., Tokyo, Japan). As for the test among the three groups, one-way analysis of variance was first performed for the group after normal distribution, and then the Bonferroni test was performed as a post hoc test. The Kruskal-Wallis test was performed for groups that did not follow the normal distribution, and then the Bonferroni test was performed as a post hoc test. Continuous variables are presented as mean \pm standard deviation (SD) or mean \pm standard error of the mean (SEM), whereas groups were compared using Student's t-test or the Mann-Whitney $U$ test unless stated otherwise. Categorical variables are presented as percentages, and the analyses were done by applying Fisher's exact test. $P$ values were two-sided, and $P<0.05$ waswe considered statistically significant.

\section{Ethical statement}

Informed consent was obtained from all students after an explanation was provided of the study's purpose and procedures. The study protocol was reviewed and approved by the Ethics Committee of Hamamatsu University School of Medicine on March 6, 2017 (number 16-280). Further, the investigation was conducted in accordance with Good Clinical Practice principles in adherence to the Declaration of Helsinki.

\section{Results}

\section{Study participants}

A total of 121 medical students with no endoscopy experience were included (Group A, 37; Group B, 40; and Group C, 44). The backgrounds of the 121 medical students are as follows: 76 males with an average age of $24.5 \pm 3.0$ years and eight lefthanded persons (10.5\%); 45 females with an average age of
$23.4 \pm 1.7$ years and four left-handed persons (8.9\%). In Group $A$, the instructor instructed participants how to hold the endoscope and move the angle. In Group B, the instructor showed students how to use the four-position method. In Group C, students actually touched the endoscope, performed a four-position method, and then used the simulator to insert the endoscope. For each group, 22 males and 15 females in Group A had an average age of $24.1 \pm 2.41$ years and there were five left-handed persons (13.5\%). Group B consisted of 26 males and 14 females with an average age of $24.3 \pm 3.2$ years and three left-handed persons (7.5\%). Group C consisted of 28 males and 16 females with an average age of $23.8 \pm 2.2$ years and four left-handed persons ( $9.1 \%)$. There were no significant differences in sex ratio, age, or left-handedness between the groups.

\section{Time to arrive at each point}

Times from the start of endoscope insertion to reaching the cardia, greater curvature of the upper gastric body, pylorus, and descending duodenum were measured and compared among groups. Arrival time to the cardia (1) was not significantly different among the three groups (mean 18.9, 17.2, and 15.1 seconds, respectively); however, with regard to other targets including the upper part of the stomach body (2) (mean $39.2,38.0$, and 30.8 seconds, respectively), the pylorus (3) (mean $64.4,60.3$, and 47.6 seconds, respectively), and the descending duodenum (4) (164.4, 149.5, and 127.3 seconds, respectively), Group $C$ reached the sites significantly more quickly than Groups A and B $(P<0.05)$ ( $>$ Fig.4). There was no time limit for the task in this study. All students were able to complete all procedures.

\section{Time taken to pick up the clip using forceps.}

Next, time from insertion of the endoscope to grasping of the clip placed on the fornix with forceps twice per person was measured and compared among groups. Medical students per-

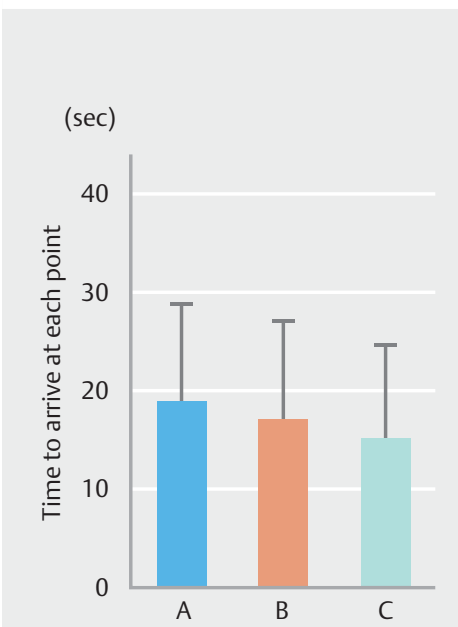

(1)

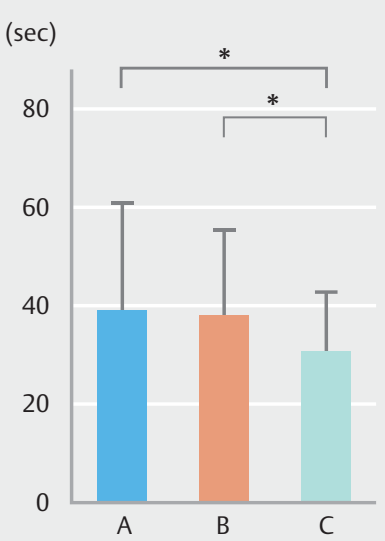

(2)

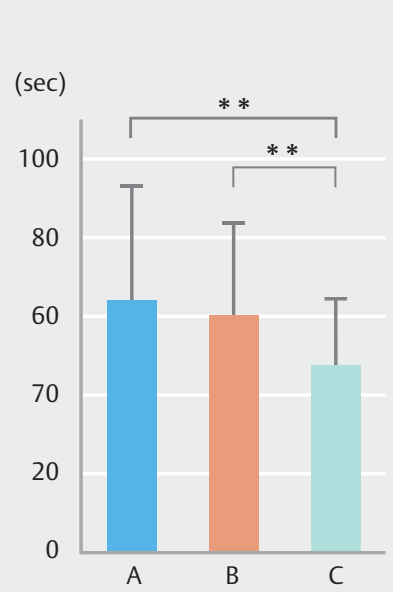

(3)

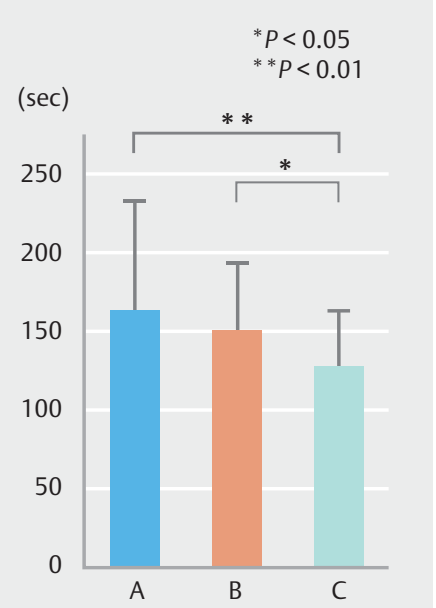

(4)

- Fig. 4 Time to arrive at each point. The transit times to the cardia (1), upper part of the stomach body (2), pylorus (3), and descending duodenum (4) are shown. 

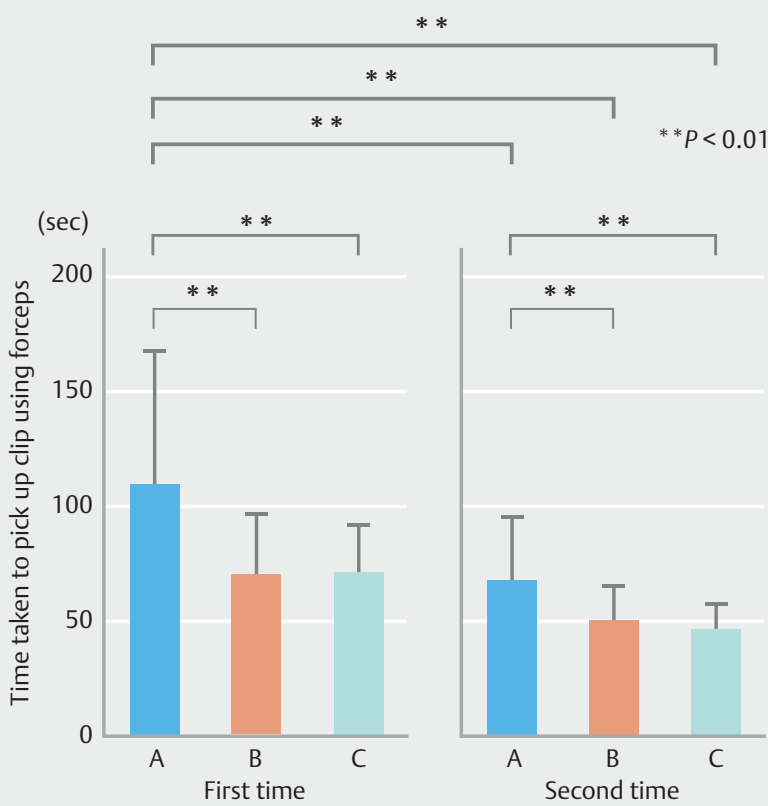

Fig. 5 Time taken to pick up the clip using forceps. The first and second times until the clip is picked up are shown.

formed endoscopy control and forceps manipulation at the same time by themselves. In all groups, the second time clip grasping time was significantly shorter than the first time ( $\bullet$ Fig.5). The times were significantly shorter in Groups B (70.8 sec, $51.2 \mathrm{sec})$ and C (71.6 sec, $45.8 \mathrm{sec})$ than in Group A $(110.2 \mathrm{sec}, 68.9 \mathrm{sec})(\boldsymbol{\nabla}$ Fig. 5). There was no time limit for the task in this study. All students were able to complete all procedures.

\section{Graded difficulty level of endoscope use before and after practical training}

We also asked all medical students who participated in the study before and after training using simulators about their impressions of the difficulty of the endoscopy techniques. Before training, there was no significant difference among Groups A (mean, 3.27), B (mean, 3.40), and C (mean, 3.07) ( $\triangleright$ Table 1). Although participants in all groups felt the techniques were significantly easier after than before training, significantly more students in Group B (mean, 2.03) and Group C (mean, 1.98) compared to Group A (mean, 2.81) felt that endoscopy was easier after instruction ( $\bullet$ Table $\mathbf{1}$ ).

\section{Discussion}

As a general instruction method for beginner endoscopists, the instructor first explained in detail the mechanism of the endoscope, such as how to move its dial, use suction, and operate the air supply buttons. The beginners then practiced endoscope operation, insertion, and observation by using a simulator. However, beginners cannot visualize the esophagus and stomach well because they do not understand how to efficiently rotate the endoscope tip in the digestive tract. Endoscopy experts unconsciously rotate the endoscope tip freely in the digestive tract. When teaching new operators to perform endoscopy, the instructor explains how to move the dial to move the angle and how to use the air supply/suction button; however, there seems to be little teaching about the spatial position of the left hand.

In this study, we first measured and compared the passage of time to each part using the endoscope in Group A, which was taught only the endoscope operation; Group B, which was taught the four-position method; and Group C, which actually practiced the four-position method by using the endoscope. There was no difference in time to reach each site between Groups A and B, but there was a significant difference between Groups $A$ and $C$. Interestingly, there was also a difference in endoscope arrival time between Groups B and C.

Next we examined the difference in time to grip a clip placed in the stomach using forceps among groups. Two trials were conducted, and both were significantly faster in Groups B and $C$ than in Group A. It became clear that it is useful to understand the concept of the four-position method for observation as well as procedures using devices such as biopsy forceps. Although there was no difference between Groups B and C in this

- Table 1 Graded difficulty level of endoscope use before and after practical training

\begin{tabular}{|c|c|c|c|c|c|c|c|}
\hline \multirow[b]{2}{*}{ Point } & \multirow[b]{2}{*}{ Difficulty level } & \multicolumn{3}{|c|}{ Before training } & \multicolumn{3}{|c|}{ After training } \\
\hline & & $\begin{array}{l}\text { Group A } \\
(n=37)\end{array}$ & $\begin{array}{l}\text { Group B } \\
(n=40)\end{array}$ & $\begin{array}{l}\text { Group C } \\
(n=44)\end{array}$ & $\begin{array}{l}\text { Group A } \\
(n=37)\end{array}$ & $\begin{array}{l}\text { Group B } \\
(n=40)\end{array}$ & $\begin{array}{l}\text { Group C } \\
(n=44)\end{array}$ \\
\hline 5 & very difficult $(\mathrm{N})$ & 0 & 0 & 0 & 1 & 0 & 0 \\
\hline 4 & difficult (N) & 13 & 16 & 7 & 5 & 1 & 0 \\
\hline 3 & somewhat difficult (N) & 21 & 24 & 33 & 20 & 10 & 10 \\
\hline 2 & moderate $(\mathrm{N})$ & 3 & 0 & 4 & 8 & 18 & 25 \\
\hline 1 & easy $(N)$ & 0 & 0 & 0 & 3 & 11 & 7 \\
\hline \multirow[t]{2}{*}{0} & very easy $(\mathrm{N})$ & 0 & 0 & 0 & 0 & 0 & 2 \\
\hline & $\begin{array}{l}\text { Mean points }=(\mathrm{N} \times \text { Point } / \text { Total number } \\
\text { of people in each group })\end{array}$ & 3.27 & 3.40 & 3.27 & 2.81 & 2.03 & 1.98 \\
\hline
\end{tabular}


study, participants in Group B actually performed endoscopy at the time of the observation test using the simulator; at that time, Group B understood the concept of the four-position method and the actual required movements.

An important factor in mastering a procedure quickly is to have a positive image like "It seems easy" or "I can do it well" without having a negative image like "It seems difficult" or "I'm not going to do it well" of the procedure. In this study, we conducted a questionnaire survey of the perceived endoscopy difficulty before versus after the actual endoscopy simulation. We found no difference among the three groups before the simulation training, but after the training, the perceived difficulty was decreased in Groups B and C, in which the four-position method was taught. The fact that the participants were able to operate the endoscope more efficiently than expected by being taught the four-position method is thought to be a contributing factor.

Some recent simulators have virtual reality devices linked to computers that lack the endoscope tip [11-13]; however, to learn the delicate movement of the endoscope tip that accompanies movement of the left hand, a simulator using an actual endoscope is more useful. Also, to allow better endoscope operation, it is necessary to practice using the simulator repeatedly over time. However, understanding the four-position method will reduce unnecessary operations, so it will be possible to learn techniques to observe the upper gastrointestinal tract in a relatively short period of time.

There were some limitations in this study. There are few previously validated measurements of endoscopic insertion time for beginners in upper gastrointestinal endoscopy, and some of the landmarks used as arrival times in this study have not been substantiated in previous studies. Second, in this study, the time required to pick up a clip using forceps was evaluated as an endoscopic navigation skill, but this metric has not previously been verified.

\section{Conclusion}

In this study, we taught medical students the four-position method using a simulator and examined how it affected insertion, observation, forceps use, endoscope use, and perceived difficulty of upper gastrointestinal endoscopy. Endoscopy techniques such as endoscopic mucosal dissection are widely used in current practice and require advanced skills, but most lefthand movements to perform these endoscopy procedures are considered skills that are an extension of the four-position method. Increasing awareness of the four-position method will help facilitate the technical growth of beginner endoscopists.

\section{Competing interests}

The authors declare that they have no conflict of interest.

\section{References}

[1] Inoue M. Changing epidemiology of Helicobacter pylori in Japan. Gastric Cancer 2017; 20: 3-7

[2] Nagami Y, Ominami M, Otani K et al. Endoscopic submucosal dissection for adenocarcinomas of the esophagogastric junction. Digestion 2018; 97: 38-44

[3] Leung WK, Wu MS, Kakugawa Y et al. Asia Pacific Working Group on Gastric Cancer. Screening for gastric cancer in Asia: current evidence and practice. Lancet Oncol 2008; 9: 279-287

[4] Joo NS. Esophagastroduodenoscopic training in the family physician residency program. Korean J Fam Med 2010; 31: 585-586

[5] Lee KM, Choi SR, Jang Bl et al. Education and training guidelines for the Board of the Korean Society of Gastrointestinal Endoscopy. Korean J Gastrointest Endosc 2011; 42: 207-214

[6] Chun JH, Yoon YS, Oh SW et al. Current state and demand of esophagogastroduodenoscopy training in family practice residency programs. J Korean Acad Fam Med 2003; 24: 1092-1098

[7] Coleman WH. Gastroscopy: a primary diagnostic procedure. Prim Care 1988; 15: 1-11

[8] Ponich T, Enns R, Romagnuolo J et al. Canadian credentialing guidelines for esophagogastroduodenoscopy. Can J Gastroenterol 2008; 22: $349-354$

[9] Lee SH, Park YK, Cho SM et al. Technical skills and training of upper gastrointestinal endoscopy for new beginners. World J Gastroenterol 2015; 21: 759-785

[10] Fudman DI, Falchuk KR, Feuerstein JD. Complication rates of traineeversus attending-performed upper gastrointestinal endoscopy. Ann Gastroenterol 2019; 32: 273-277

[11] Ferlitsch A, Schoefl R, Puespoek A et al. Effect of virtual endoscopy simulator training on performance of upper gastrointestinal endoscopy in patients: a randomized controlled trial. Endoscopy 2010; 42: 1049-1056

[12] Shirai $Y$, Yoshida T, Shiraishi R et al. Prospective randomized study on the use of a computer-based endoscopic simulator for training in esophagogastroduodenoscopy. J Gastroenterol Hepatol 2008; 23: 1046-1050

[13] Van Sickle KR, Buck L, Willis R et al. A multicenter, simulation-based skills training collaborative using shared Gl Mentor II systems: results from the Texas Association of Surgical Skills Laboratories (TASSL) flexible endoscopy curriculum. Surg Endosc 2011; 25: 2980-2986 